\title{
La reescritura de La infancia en Los días ocultos de Luis Oyarzún ${ }^{1}$ \\ Rewriting La infancia in Luis Oyarzún's Los Días Ocultos
}

\author{
Lorena Amaro Castro \\ Pontificia Universidad Católica de Chile \\ lamaro@uc.cl
}

\section{Resumen:}

El filósofo Luis Oyarzún escribió dos novelas de carácter autobiográfico en que presenta las percepciones de un niño de provincia: La infancia (1940) y Los días ocultos (1955). Críticos como Roberto Hozven, Leonidas Morales y Olga Grau manifiestan que la segunda es una reelaboración de la primera. El siguiente artículo desarrolla una comparación entre ambos textos, buscando dilucidar y comprender cuáles son las diferencias entre ellos y en qué medida revelan una maduración en la escritura e inquietudes de un autor que ocupa un lugar hasta ahora marginal en la construcción canónica filosófica y literaria chilena.

Palabras clave: infancia, reescritura, canon, escritura autobiográfica, intimidad.

\begin{abstract}
:
Philosopher Luis Oyarzún wrote two autobiographical novels that present the perception of a child from the province: La infancia (1940) (Childhood) and Los días ocultos (1955) (Hidden Days). Critics such as Roberto Hozven, Leonidas Morales and Olga Grau state that the second novel is a new version of the first one. This article compares both texts, seeking to elucidate and understand the differences between them and examining, in both cases, the extents to which they reveal a more mature writing, as well as the concerns of an author that until today holds a marginal place in the construction of a Chilean philosophical and literary canon.
\end{abstract}

Keywords: Childhood, Rewriting, Canon, Autobiographical Writing, Intimacy.

1 Este artículo ha sido escrito gracias al financiamiento de Fondecyt, en el marco del proyecto Fondecyt Regular N 1120654 "Fronteras de infancia, género y nación en diez novelas autobiográficas chilenas" (2012- 2013), en que su autora participa como investigadora responsable y Ghislaine Arecheta y Francisca Lange como coinvestigadoras. 


\section{Introducción: la singularidad de un autor}

“Pueden coincidir la escritura de la propia infancia con la infancia de la propia escritura?”, se pregunta Olga Grau (183) en un artículo sobre la temprana narrativa de Luis Oyarzún (1920 - 1972). Recojo la interrogante en este trabajo, en el que busco entender las relaciones entre la primera novela del conocido filósofo -publicada en 1940, sin reediciones-, titulada significativamente La infancia, con otra obra suya, de 1955, Los días ocultos, en el contexto más amplio de su escritura.

Como plantean Grau, Leonidas Morales y Roberto Hozven, ambos son textos de matices autobiográficos: ambos transcurren en un pueblo de la zona central chilena (Oyarzún creció en Santa Cruz) y refieren la relación de un niño de cuatro años, observador e imaginativo, con su entorno familiar y objetual. Oyarzún no desplaza ni por segundos, entre un libro y el otro, la precisa locación temporal de su protagonista, los cuatro años, remontándose de este modo a una infancia prelingüística, que se manifiesta sobre todo como mirada, como sensación, como cuerpo sensible. En ninguno de estos relatos, por otra parte, se puede hablar de una autobiografía desde la perspectiva pragmática, contractual, propugnada por Philippe Lejeune, dado que el código onomástico no coincide exactamente con los nombres reales del autor y sus familiares; los dos relatos se presentan como novelas, subrayando a propósito su carácter ficcional. Las semejanzas son tantas, en suma, que los críticos mencionados hablan de una reescritura. El punto no ha sido discutido hasta hoy, probablemente porque ambas narrativas ocupan un lugar menor en el canon literario chileno. Considero, sin embargo, que se trata de textos de mucho interés en el desarrollo de una mirada intimista, la que rescata y exhibe a ese sujeto desafiante y subalterno que es, sin duda, el niño.

El lugar marginal de Oyarzún en el canon literario chileno -su inscripción se debe principalmente a la publicación de su Diario íntimo, género considerado por muchos ancilar- se reproduce también, hasta cierto punto, en el ámbito filosófíco. Pocas veces, al menos hasta después de 1980, se cruza en el pensamiento filosófico sistemático de los académicos nacionales la cuestión de la literatura. Por otra parte -y en contraste con sus compañeros de hornada intelectual-, Oyarzún se aproxima a la filosofía sin guardar distancias, arriesgando una intimidad que, rescata Cecilia Sánchez, está ausente del pensamiento académico en los años en que Oyarzún desarrolló su carrera: “a diferencia de los literatos e historiadores, los filósofos no relatan sus experiencias ni los avatares de su quehacer. Podría decirse que el tiempo de su pensar, lo que les pasa, tiene las marcas del transcurrir de otra historia" (24). Sánchez señala la excepcionalidad del caso de Oyarzún, percibiendo y rescatando la extranjería de un pensamiento que en vez de sublimar en su discurso aspectos como el lugar de enunciación, el sexo y el cuerpo, neutralizando su voz, deja ver inesperadamente sus inflexiones. La institución filosófica chilena, que Sánchez ha investigado largamente, produce de este modo un discurso que suena "parecido al timbre de la voz del así llamado género masculino", pero en que este es realmente negado para propiciar la voz del "Hombre", el cual "es sujeto, es persona y es 
libre, precisamente porque su sexo ha sido borrado" (Sánchez, Escenas del cuerpo escindido 116). "Este 'Hombre' no es más que el anthropos, suerte de castrado y Frankenstein compuesto únicamente de las partes superiores del cuerpo. El resto del cuerpo ha sido mutilado, privado de las partes inferiores a fin de ejercer con legitimidad el habla del logos. Pese a la violencia que cobija, ese cuerpo no exhibe heridas ni carencia alguna" (Sánchez, Escenas del cuerpo escindido 112).

Cecilia Sánchez analiza las sutiles referencias de Oyarzún a su homosexualidad -las que aparecen consignadas en su Diario y que son rescatadas, además, por Juan Pablo Sutherland en la antología sobre la homosexualidad en la literatura chilena A corazón abierto-, procurando explicar el lugar que ocupó su trabajo en el ámbito filosófico. La aparición de Oyarzún en ese ambiente constituye un trozo de historia queer que debe ser leído como algo más que un inciso de la historia literaria y en este caso, también, filosófica: su posibilidad, su aparecer, resulta central para entender la conformación del campo cultural, sus silencios y sus exclusiones: “[...] la inclinación sexual de Oyarzún forma parte de su relato, pese a que sus comentaristas en el ámbito de la filosofía tienden a borrarla, en parte debido a la necesidad de obedecer a la institución del 'sujeto trascendental"', escribe Sánchez ("Filosofía, literatura e intimidad en la escritura de Luis Oyarzún" 29). Es, pues, desde esta identidad, como también desde la figura del niño o sus interrogaciones sobre la filosofía, elevadas desde una Latinoamérica pobre y atrapada en su soledad, que Luis Oyarzún desafía la heteronormatividad de su medio y también las huellas del positivismo en la institución filosófica.

Su modo de trabajar también contrasta con el de sus colegas. Sánchez opone dos modelos, encarnados en Jorge Millas, amigo de Oyarzún desde los tiempos del Instituto Nacional Barros Arana (INBA), y en el autor de La infancia: uno, el del estudioso metódico, sistemático; en tanto el otro, el intelectual de variados intereses que, sin duda, hoy sería juzgado como "carente de obra mayor", como un "académico con escaso rendimiento cualificable" (Sánchez, "Filosofía, literatura e intimidad en la escritura de Luis Oyarzún” 32).

Oyarzún fue, pues, un creador inclasificable, por sobre todo, un creador; en él es intensa, según escribe Jorge Millas, la pasión de ver, una mirada que se desplaza, excéntrica, fuera del centro perfilado por la sistematicidad filosófica, impostando la mirada del niño o del animal, extremando la visión en su acercamiento al mundo material. De ahí la dificultad de clasificar su obra y precisar el lugar desde el cual se puede hablar de ella: Sánchez presenta las dudas sobre el Diario íntimo, a menudo, dice, considerado una "no-obra" (que contiene en sí bosquejos de obras que serían publicadas en vida del autor, como Temas de la cultura chilena), o bien una obra menor; el problema es si se trata de "la escritura de un narrador, de un poeta o de un pensador filosófico" (Sánchez, "Filosofía, literatura e intimidad en la escritura de Luis Oyarzún" 31). Esta extranjería, su acontecer in-between, es lo que torna radicalmente otro el legado del autor y deseable la relectura de sus primeros libros, en los que podríamos preguntarnos, también, quién es el que prima: ¿el poeta, el narrador, incluso el diarista que ya se expresa por medio de fragmentos fetichistas y sutiles silencios, tatuando con ellos la infancia? 
Por cierto, la existencia de las dos novelas (las únicas publicadas por el autor) reafirman la excentricidad de la escritura de Oyarzún. Quienes han estudiado su producción coinciden en subrayar el carácter fragmentario de su escritura, estética que se vincula particularmente a lo que Alberto Giordano llamaría recientemente el "acto diarístico": "esos momentos singulares en los que la aparición de un gesto enunciativo que muestra más de lo que la notación registra hace que la imagen del diarista, esa que fue construyendo día a día hasta darle consistencia de un carácter, se desgarre" (136), esto es, el emerger de una subjetividad desdoblada y significativa en sus más pequeños detalles, involucrada en cada observación que realiza, íntima y también, muchas veces, dolorosamente extranjera. Sus finas observaciones de esteta lo singularizan en el campo literario nacional: "el fragmentarismo del género, la condición 'parasitaria' o 'residual' de su escritura, se convierten, en la sorprendente realización de Oyarzún, en las vías de acceso a un inédito 'placer del texto' (Barthes), para mí, desconocido hasta entonces en la literatura chilena” (Morales). Esto, y su adentramiento en los modos expresivos intimistas, hacen de él algo más que un "partidario de la modernidad y de los modernismos" (Sánchez, "Filosofía, literatura e intimidad en la escritura de Luis Oyarzún” 22): con su escritura, él mismo se adelanta en lo que atañe a presentar la cara íntima no solo de una experiencia infantil, sino que de un relato de carácter autobiográfico en un país donde el sujeto público, inserto en una sociedad heteronormativa y patriarcal, encuentra la prohibición, como varón, a hablar desde ahí, desde esa conciencia inaugural y secreta, también frágil, de los niños.

Solo otros tres autores se animan a incursionar en este ámbito durante ese periodo: el actor Lautaro García con su Imaginero de la infancia (1935), Augusto D’Halmar, quien publicó sus memorias como las de Cristián Delande en La Nación entre 1939 y 1940, textos que en 1975 Alfredo Calderón reuniría con el título Recuerdos olvidados, y la narradora María Flora Yáñez, autora de Visiones de infancia (1947). La vocación de García pareciera autorizarlo a hablar desde la imaginación y las fantasmagorías infantiles; Flora Yáñez recupera las escenas domésticas, los rincones de una niñez atrapada por el género y también el buen tono familiar y D'Halmar transgrede la normatividad de la época no solo por su homosexualidad (como el propio Oyarzún), sino que también por sus excentricidades de viajero inagotable.

Pero son pocos los autores en Chile que exhiban como Oyarzún las marcas de su proceso creativo, particularmente en el orden de la escritura íntima. No es raro que los autobiógrafos -remontémonos a Rousseau- escriban una y otra vez el relato de sus vidas; pero en Chile el número de ellos es limitado - pienso en Inés Echeverría, en María Flora Yáñez, en Joaquín Edwards, en Benjamín Subercaseaux, en José Donoso-. Sobre el caso de Oyarzún, en que además lo autobiográfico se encuentra encriptado pero aun así dolorosamente visible, cabe preguntarse, pues, por qué dos libros distintos, de diverso título, y no una reedición de La infancia. 


\section{La infancia y Los días ocultos: ¿un mismo libro?}

Como ya he planteado, diversos autores sostienen que Los días ocultos reelabora en lo sustancial la primera novela de Oyarzún. Sin embargo, se observan modificaciones significativas, sobre las cuales no se ha dicho mucho hasta ahora. Críticos como Grau, Morales y Hozven han subrayado más bien lo coincidente de las tramas y el estilo de estas dos producciones y el hecho de que Oyarzún haya ido labrando ya en esas obras las formas expresivas que caracterizan su producción ensayística, como la fragmentariedad, el uso de la frase corta y el lirismo (Grau), la comparación, la sinestesia y la hipérbole (Morales).

Efectivamente, los parecidos entre ambos textos son remarcables. La infancia es una narración en tercera persona, focalizada en un niño de cuatro años, Eugenio ${ }^{2}$, quien vive con su madre, su padre y sus hermanos en un pueblo. A través del estilo indirecto libre, el narrador insiste en revelar una conciencia acosada por fantasmas y pesadillas. Es un niño enfermizo, débil, fuertemente vinculado a su madre. Ella sufre silenciosamente, como un ángel del hogar provinciano, los abandonos y la agresividad de su marido. En su análisis de la novela, Roberto Hozven se detiene particularmente en este personaje; para él, La infancia es una nouvelle que "puede ser leída como la biografía triste de los primeros años de matrimonio de una joven madre de 24 años quien, en su desencanto, torna a su hijo primogénito en el sustituto inconsciente, en el suplefaltas de sus apetencias, nostalgias y deseos íntimos más frustrados" (33). Los días ocultos retoma a la madre, pero con otro tono (es indudable la pérdida de protagonismo). Su narrador, en primera persona, es Eugenio. La historia se ambienta en un espacio muy similar y el niño es igualmente débil y enfermizo. Aparentemente solo cambian los nombres de algunos personajes, se matizan algunas situaciones, pero se mantiene lo fundamental, con distinto título. Escribe Morales:

La infancia [...] pretende ser una ficción bajo la forma de la novela. Pero el carácter autobiográfico de la narración, y su proximidad por lo tanto al género del diario íntimo, apenas lo disfrazan el cambio de nombre de los personajes y el uso de la tercera persona. En Los días ocultos (1955) Oyarzún retoma, ahora desde la primera persona, el tema autobiográfico del libro anterior. El tono de intimidad, el espacio cotidiano y las tensiones del mundo del niño protagonista, que oscila entre sentimientos de beatitud y de miedo (con la madre como centro luminoso, pero frágil, de un paraíso corroído por la incertidumbre), son los mismos. Incluso el final de ambas evocaciones es textualmente casi coincidente. De manera pues que estos libros, o son publicaciones parciales del Diario, o están armados con trozos suyos, o reelaboran algunas de sus anotaciones, o remiten al ámbito de las constantes de su pensamiento, o, por el

2 El nombre está en la familia de Oyarzún, uno de sus sobrinos se llama así. No he podido corroborarlo, pero pienso que es probable que llevaran este nombre otros miembros de la familia, incluso él mismo. 
contenido autobiográfico, se sitúan en la vecindad del género. Pero es importante además considerar las proyecciones de un procedimiento constructivo consustancial al diario íntimo: la formación de conjuntos textuales mediante fragmentos (Morales).

Hozven, quien califica ambos textos de Oyarzún como relatos confesionales (y no como novelas), repite esta lectura de continuidad entre los dos. Los días ocultos, dice, "retoman el mismo tema y personajes, aunque con mejor construcción narrativa" (33). Y agrega:

La figura de la madre, la 'mamacita' protagonista omnipresente de $I$ [... disminuye su presencia en $D O$ a un capítulo de dos páginas más apariciones episódicas en los restantes. De ráfaga angustiosa en $I$, la madre se convierte en un aire más domesticado en los DO. Esta es la gran diferencia entre ambos relatos confesionales. Sin embargo, la aparición disminuida de la madre no borra la complicidad de Eugenio con ella (34).

Grau insiste también en los parecidos entre ambos textos, planteando que en $\mathrm{La}$ infancia se develan señales que serán características de su producción posterior, lo que hace del título de la novela prácticamente una reflexión metaliteraria: "Es posible -dicepensar La Infancia, libro sobre la experiencia de la infancia temprana, como la infancia de la escritura de L. Oyarzún, porque da las señales de una opción escritural que se mantendrá a través del tiempo" (184). Más adelante agrega, sobre Los días ocultos, que se trata de una elaboración escritural

\footnotetext{
que deja atrás cierto abigarramiento en las imágenes que construyen las experiencias de la infancia y que otorga a la narración un mayor realismo. La obra limpia compone con un principio de mayor economía textual que la del libro anterior, pretende una escritura más llana, pero pierde parte del lirismo que caracteriza fuertemente al primero y de la fascinación extrema por el lenguaje que se explora [...] El primer texto resuena en el segundo, pero sometido a un control, que podríamos señalar como un control del yo (187).
}

Grau, no obstante, es la única que hace alusión al contexto de la autoría, que ha cambiado entre un libro y otro: "L. Oyarzún tiene 35 años de edad en el momento de publicar Los días ocultos (1955), publicación que convive con otros escritos y afanes de su vida académica" (187). Es interesante, nuevamente, la perspectiva abierta por Sánchez, cuando remarca en la escritura de Oyarzún la aparición de una interioridad que si bien "parece enmarcarse en un subjetivismo centrado en el yo personal" (Sánchez, "Filosofía, literatura e intimidad en la escritura de Luis Oyarzún" 30), revela finalmente que "el autor como principio de unidad pierde significado en la medida en que deja de ser una persona física y pasa a ser 'escritura"' (30), dejando de lado, dice Sánchez, su “yo real”, transmutado en esa escritura. En estas reescrituras.

El Diario de Oyarzún y las publicaciones que arrancan de esos fragmentos revelan hasta qué punto la reescritura constituye un procedimiento constructivo importante en el 
trabajo del autor. Con el término reescritura quiero significar aquí "la acción, el hecho de reescribir", de "dar una nueva versión a un texto ya escrito" o "reinventar, dar una nueva versión de alguna cosa" (Gignoux). En un texto que despeja con mucha precisión las relaciones entre intertextualidad y reescritura, la crítica Anne-Claire Gignoux profundiza en este procedimiento, distinguiendo entre el texto ya escrito como borrador y el texto ya publicado, asignando al primero la idea de réécriture, así escrito, para distinguir el manuscrito que interesa a los estudios genetistas, del texto ya publicado por una operación de récriture. Plantea que no se trata de lo mismo en cada caso, habida cuenta del funcionamiento de los textos en el campo literario ${ }^{3}$. En tanto las vacilaciones y tachaduras del manuscrito forman parte de todo proceso creativo, el procedimiento por el cual se vuelve sobre un texto ya publicado, de otros autores o propio, implica una particular intencionalidad, que busca conferir nuevos sentidos a una obra que ya ha tenido contacto con los lectores (Gignoux). Por otra parte, desde un punto de vista estilístico, la reescritura, en este sentido, tiene además una especificidad que no tiene la intertextualidad (por ejemplo, el uso de una cita aislada, dice Gignoux): toda reescritura de un texto publicado supone una relación intertextual, pero no toda relación intertextual entraña una reescritura. En este sentido se puede decir que el caso de Oyarzún implica ambas formas de relación textual.

El placer de la escritura, sus búsquedas, como también su soledad, resultan para todo escritor alicientes importantes de una reescritura, pero revisando los análisis practicados a los textos de Oyarzún, en concreto a estas dos novelas, está del todo ausente la pregunta sobre el sentido: por qué repetir, por qué volver a las escenas traumáticas de una infancia psicasténica. Por qué publicar esa reescritura con un nuevo título, pensando en que $\mathrm{La}$ infancia fue un libro de juventud, de escaso tiraje y, probablemente, escasa recepción ${ }^{4}$, que hasta el día de hoy permanece sin reeditar. Por qué presentar Los días ocultos, así, con otro título, como un libro distinto, si en realidad parecen semejarse tanto. ¿Quería, quizás, Oyarzún, que ese primer librito suyo fuera olvidado? Desde su punto de vista, ¿había diferencias sustanciales que era preciso remarcar, cambiando el título y presentando el libro como otro, esperando, tal vez, una lectura que descubriera como pistas, huellas, las diferencias entre uno y otro texto?

Sostengo que hay tres hechos - con sus consecuencias textuales- que parecen fracturar la identidad entre uno y otro relato: 1) el distanciamiento del surrealismo y el ambiente creativo que había rodeado la elaboración de la primera novela, en los años de la Segunda Guerra Mundial; 2) la experiencia del viaje (Oyarzún viaja en 1949 a Inglaterra, a hacer estudios de posgrado en Filosofía), que diferencia el punto de vista y la estrategia

3 Cito el texto de Gignoux en el original: "La récriture ou réécriture est « l’action, le fait de réécrire », c'est-à-dire de « donner une nouvelle version d'un texte déjà écrit » ou de « réinventer, donner une nouvelle version de quelque chose » (19)". "Cet aspect mérite qu’on s’y attarde: « texte déjà écrit » peut signifier aussi bien « texte déjà publié » que « texte manuscrit ». Or, la démarche n’est pas la même dans les deux cas" (4).

4 En una de las cartas cursadas entre el autor y un amigo suyo, este último le pide a Oyarzún que le haga llegar algunos ejemplares de La infancia porque ha encontrado entre quiénes comercializarlos en la ciudad de San Fernando (v. Oyarzún Epistolario). 
narrativa entre ambas novelas; 3) la difusión del trabajo de Oyarzún como intelectual, quien ya era bastante conocido hacia 1955, posición que quizás hacía deseable acallar, en una narrativa de carácter reconocidamente autobiográfico, los aspectos más polémicos e íntimos de la infancia y la vida familiar. A continuación me centraré en estos aspectos, para luego intentar comprender la elaboración de estas narrativas en el marco de la producción del autor, volviendo a la idea de "la infancia de la escritura" a la que se refiere en su interesante artículo la filósofa Olga Grau.

\section{Un aroma de lejanía}

En "Crónica de una generación” (ensayo incluido en Temas de la cultura chilena), podemos conocer algo más sobre ese ambiente intelectual en que es creada La infancia. El encuentro con quienes serían grandes amigos, Nicanor Parra, Jorge Millas y Jorge Cáceres, constituye para su autor una revelación: "No era yo un niño loco, o por lo menos no era el único loco en el mundo" (160). La Vie Immédiate, de Paul Eluard -donde se cursan fuertes críticas a la vida burguesa-, así como una serie de otras lecturas surrealistas, se convierte en su evangelio. No es extraño, pues, que la nouvelle esté teñida de presagios y revelaciones, en que la exploración del lenguaje resulta fundamental, proyectando en sus resultados una suerte de delirio empantanado en una escritura obsesiva y fetichista. Como bien precisa Hozven, la figura de la madre es fundamental (todo texto surrealista debe tener la musa que lo conecte con realidades impensadas y trascendentes), pero también lo son los objetos mismos. La infancia se vincula, de este modo, con una estética surrealista que ante todo busca una exploración perceptual de la realidad (de ahí la lectura de Grau, acerca de un mayor realismo de Los días ocultos frente a la novela anterior), una anhelada e imposible fusión con las materias, aspecto que Oyarzún alaba, por ejemplo, en la poesía de Gabriela Mistral.

Por otra parte, años más tarde, en un ensayo, él discute la idea de que la infancia sea "una edad perfectamente integrada que se satisface a sí misma"; por el contrario, dice, "se olvidan las ansiedades, las angustias, los deseos sin forma que también la caldean y que no pueden hallar otra desembocadura que el aislamiento en medio de los juegos de los otros niños, los sueños y la tristeza" (Oyarzún, Temas de la cultura chilena 158). A esta mirada, que dice relación con un sustrato experiencial, se suma, a mi entender, el eco de las lecturas simbolistas y también surrealistas con las que Oyarzún encontró precisamente en los años de redacción del libro (son explícitas sus referencias a Eluard, también al acercamiento, a través de Jorge Cáceres, al mundo de la Mandrágora). Como en los textos surrealistas, o como escribió Walter Benjamin sobre el acontecer en los textos surrealistas europeos, su escritura fragmentada va revelando verdaderas iluminaciones profanas. Sueño y creación se acercan y las cosas, los objetos cotidianos revelan su doble o triple faz, abalanzándose insistentemente sobre el pequeño protagonista, llegando a entablar diálogos insólitos: 
Dentro del sueño, consciente de que sueña y quiere despertar, se pierde en las encrucijadas y comienza a vagar alrededor de una estatua de mármol que late. Todo emerge muy tibio y va poniéndose rojo, las cosas lo detienen como una membrana que lo rodea y va comprimiéndose hasta adquirir su forma y hacerlo otro, dormido, pero vivo para siempre. Allí está la ventana, más acá duermen sus padres, pero esto en verdad no existe. Lo verdadero es él, captado por la malla de los objetos que crecen y lo devoran [...] Recuerda los juegos y los aviones de papel sobre el patio caen ahora sobre su cuerpo y ríen en su vuelo. El papel se reblandece y conversa burlándose (Oyarzún, La infancia 87).

Pero el mismo narrador advierte que los objetos "son más agudos en su lejanía" (Oyarzún, La infancia 19); y, en este sentido, la madre resulta, en la percepción infantil, el objeto por excelencia, también el más distante. Es señalada por sus vestimentas, sus muebles, sus joyas, que metonímicamente indican su presencia/ausencia. El límite lejanísimo de la madre contagia a los objetos que son de su propiedad, los que se hallan todos bajo un mismo halo: “ $\mathrm{A} A$ h, los trajes de mamá son delicados, a la distancia se pueden sentir, tienen un aroma de lejanía que lo roza al dormirse!" (Oyarzún, La infancia 16). "La silla de su madre, igual a todas las demás, tiene un pálido tinte de lejanía que la diferencia" ( $\mathrm{La}$ infancia 30). Como plantea Hozven, "Eugenio no sale de esta melancolía patológica, no renuncia a su unión amorosa imaginaria con el objeto ansiado, perdido, de la madre" (38).

Así, tanto los escorzos proustianos que abren esta narrativa crepuscular - "Es un niño lleno de miedo, en la noche" (Oyarzún, La infancia 5)-, como todo el planteamiento objetual de la novela, apuntan a la aparición de esta figura, que como bien señala Hozven, la preside. Ningún otro niño en nuestra literatura -pienso en soñadores como Alsino, o sensibles como Daniel, de Niño de lluvia ${ }^{5}$ - desarrolla una relación más intensa que la del narrador infantil de Oyarzún con esta madre aurática, pequeña y melancólica, bella. No es raro, pues, que la madre aparezca en un mundo aparte del de los demás personajes, ajena a todo y como transfigurada en una imagen fotográfica:

[...] Eugenio teme por su madre. La encuentra tan diferente al tío José y a Pablo, parece venir de otra ciudad más clara y también más triste, no debe acostumbrarse a vivir con ellos. Sobre todo, cuando Eugenio la recuerda surgiendo de un retrato de niña, vestida de estudiante, con trenzas hechas por la fría mano de la mañana. Está de pie al lado de una planta y a su alrededor domina cierto vago color de opio. En la orilla clara, abajo, hay unas letras doradas. La antigua fotografía es hecha de un material liviano y de un tinte irreal. Desde el fondo de la habitación viene una luz rosada, pero llena aún de sueño, y ella, de pie, niña, es su compañera. En sus ojos se adivina aquella realidad tan futura de su hijo mayor (Oyarzún, La infancia 31).

5 Sobre los vínculos entre la narrativa de Benjamín Subercaseaux, Mauricio Wacquez y Luis Oyarzún he escrito en el artículo "Wacquez y sus precursores" (v. Referencias). 
Evidentemente aquí se proyecta una relación de identidad entre el niño y la madre/ niña, ubicados los dos en una esfera de irrealidad en que la mirada, o más exactamente la videncia que produce el encuentro de los ojos en la foto y la mirada del niño, permite la continuidad, el flujo, la unión íntima con la madre ("su compañera"). Es interesante, en este plano, que Oyarzún eligiera el totalizador título La infancia y que no sea solo Eugenio el niño, sino que la infancia aparezca espectralmente, como un recuerdo plasmado en una fotografía, mudo, señalando así la condición misma de la in-fantia, de lo inefable. Aquella experiencia prelingüística que no puede ser representada sin traicionarla. Por otra parte, se asocia también la imagen de la infancia -la madre niña- con el sueño, subrayando una vez más la dimensión irracional, onírica, de una narrativa plagada de revelaciones. Oyarzún pareciera querer acercarse aquí a modos de conocimiento que distan, claramente, de la lógica y las búsquedas filosóficas de raigambre cartesiana, para arriesgar intuiciones que lo acercan más al mundo benjaminiano del objeto cultual (en la fotografía, el rostro, dice Benjamin, es su último asidero) y también a los escritos barthesianos.

Cuando Martin Jay expone el pensamiento benjaminiano, plantea que tanto la traducción (que fascinaba al pensador alemán), como otros conocimientos clausurados por la Ilustración (la astrología, la grafología y el pensamiento analógico abordados por él en su ensayo "La enseñanza de lo semejante"), transportan precisamente a este tipo de conocimientos latentes en el tramado conceptual de la infancia oyarzuniana, los cuales a su vez son equiparables, desde esta perspectiva, a la recuperación del recuerdo infantil. A través de la experiencia mimética (por ejemplo, el juego o la magia) y el lenguaje -pienso, por supuesto, también en la literatura- sería posible cierta forma de regreso a ese tiempo y, sobre todo, a sus formas perceptuales. De ahí el interés de Benjamin en prácticas como la escritura surrealista. Lo que busca Oyarzún es encontrar un paraíso perdido, núcleo de su pensamiento sobre la naturaleza y también la convivencia humana. Para ello es preciso sentir de otra manera, incluso devenir otro, niño o animal: "Quisiera describir realmente algo. Descubrir un objeto. Romper de un solo tajo en mí el destierro del alma humana. ¿No estamos fuera del paraíso porque no vemos? ¿Oigo a este jardín? ¿Lo veo? [...] Objetos que se me escapan. Más sabio que yo, pesado por el oro de su pelaje, un abejorro se luce al sol. Desde pequeño quise contemplar el mundo desde el interior de un animal" (75), escribe en su diario, en 1950.

Eugenio tiene cuatro años. Ello posibilita su desquiciada, intensa relación con el mundo objetual y su acercamiento a modos de saber ocultos para la razón instrumental. Por otra parte, se trata aquí del tempranísimo despertar del niño y la adquisición de una conciencia adulta, al menos en lo que refiere al inevitable quiebre del vínculo con lo materno: la separación del niño y la madre es el leitmotiv de esta narrativa, en que el padre aparece como figura protectora pero a la vez como amenaza, sombra proyectada sobre la madre y la relación madre-hijo. Ese vínculo entre la madre y el padre se proyecta, metafóricamente, en el anillo, circunferencia de la unión, penetración del vacío en que se abisma el niño reiteradamente a lo largo del libro y que pareciera querer disolver, superar, mediante el uso del lenguaje, un lenguaje poético: "Mira a su madre, le alisa los cabellos. El coge su mano, el anillo va a 
sollozar, cuán profundo parece el oro, va a volar hacia sus mejillas para acariciarlo, para ser una sola persona él y su madre. El papá se mantiene indiferente" (Oyarzún, La infancia 30).

La distancia con la madre se colma de lenguaje, de una palabra fluida, de lo semiótico, en la formulación de Kristeva. De una palabra afiebrada, como prefiero remarcar aquí, en relación con la psicastenia de Eugenio. De una palabra surreal, si pensamos en el contexto de la escritura del libro:

Algo es absolutamente azul a su alrededor. Después se duerme. Rápidamente vuelan codornices, la lluvia... mas, en el sueño no es de noche ni tampoco de día; se vive entonces aprisionado en una malva cúpula de vidrio, que a veces respira por sí misma. Una codorniz se convierte en polluelo y lo hace reír, pero también tiene miedo. Siempre está solo en sus sueños y nunca es de día en ellos. Quizás por eso aparecen los animales y los bandoleros. Las prendas de vestir se mueven y hablan, dormidas sin sus dueños. Solamente un buey está pastando... (Oyarzún, La infancia 22).

Ese paso a otra orilla, la de un paraíso latente, es el que va cincelando la infancia registrada en el libro de 1940:

ese límite con el silencio que vuelve posible la escritura. No la inefabilidad de lo no dicho, sino ese paciente deslizarse a lo largo de un borde, una frontera nunca atravesada pero siempre recorrida, contorno delineado paso a paso, costa desde donde se divisa el horizonte de la experiencia, al que no es posible acceder porque se aparta a medida que uno se aproxima a él. Es la reserva inagotable del ailleurs baudeleriano, ese estar bien tan solo en otra parte del que habla Yourcenar (Pérez).

Existe, sin duda, una relación entre la experiencia infantil y la búsqueda de ese lugar vinculado con la animalidad, con el oro, con la luz, con las metamorfosis de lo cotidiano.

En sus ensayos, Oyarzún desarrolló con interés las relaciones entre el lenguaje, la poesía y la sociedad en América Latina, en un sentido que de alguna manera dialoga con su concepción de la experiencia infantil. Tomando las ideas de Félix Schwartzmann, plantea la existencia, entre los latinoamericanos, de un "trauma primario de lo natural", una noción de lo americano como tierra del descubrimiento, lugar de lo nunca antes visto, de lo inaugural (Oyarzún, Temas de la cultura chilena 119), que dificulta a su vez las relaciones humanas, sociales. Hay un centro inexpresable de la experiencia, sobre la que escribe: "también esa substancia originaria de la vida latinoamericana, aún no descubierta por el hombre constituido por ella, es lo inexpresado, lo que resta después de todo análisis exhaustivo de la conducta humana en la América Latina; lo que, por la dificultad de su aprehensión intelectual, puede ser denominado 'lo inexpresable"' (Oyarzún, Temas de la cultura chilena 142-3). Es a esto a lo que se ve enfrentado Eugenio, tanto cuando observa el patio de su casa como cuando da sus paseos por el campo o por el mundo de los sueños, pero también cuando intenta descifrar con su mirada curiosa y anhelante el mundo de las relaciones humanas, familiares y secretas en que considera a su madre la víctima de un drama. Lo inexpresado, lo inexpresable, ocupa, pues, no solo 
los pensamientos del filósofo, sino que alumbra desde muy temprano, en plena época caótica de la Segunda Guerra Mundial y de la mano del surrealismo, la creación poética y la mirada íntima del escritor.

\section{La compulsión de los desplazamientos}

Cuando escribe sobre el Diario intimo, Leonidas Morales plantea que las anotaciones de Oyarzún son "las de un hombre que pareciera habitado por demonios (o ángeles) que maquinan sin cesar la compulsión de los desplazamientos, la avidez por los imprevistos estímulos del mundo circundante" (114).

Veo presentes en la escritura anterior a los diarios, esto es, en La infancia y Las murallas del sueño, texto poético publicado también en 1940, a esos demonios y ángeles de los que habla Morales, ávidos de la cotidianidad de las materias, pero sin embargo, flojos para maquinar desplazamientos literales. Por el contrario: los demonios y ángeles que rodean al joven Oyarzún parecen producir, más bien, una especie de fiebre estancada, que se alimenta, sin duda, de las lecturas del novel autor.

Los desplazamientos a los que alude Morales, si los entendemos, como he dicho, desde el punto de vista del viaje, forman parte recién de una experiencia posterior a 1949, en que, como se puede leer en su Diario íntimo, ya se ha iniciado el periplo vital del filósofo, los viajes y excursiones que realizará solo o en compañía de otros escritores y artistas (como Parra, como Gómez Millas). El primer gran viaje, a Inglaterra, con el fin de perfeccionar sus estudios de filosofía, es un quiebre que, a mi juicio, transforma su escritura. En Los días ocultos Oyarzún incorporará esa nueva mirada, dinámica, movediza, por lo que si bien los dos libros muestran un mismo mundo provinciano, habitado sobre todo por las figuras tutelares, también amenazantes del padre y la madre, se trata de dos textos muy distintos en sus estrategias narrativas.

La infancia, dedicada a la madre del autor, consta de 34 fragmentos (bajo números romanos) relatados, como ya se ha dicho, en tercera persona, con foco narrativo en el niño Eugenio. Los días ocultos, en cambio, posee una estructura más meditada: integran el libro 17 capítulos, con subtítulos descriptivos ("El pueblo", "La madre", "La casa", "La noche", "La mañana”, "El tío Andrés", entre otros), en que, como bien observa Hozven, Oyarzún alterna las perspectivas, entre una omnisciente, sobre el pueblo, y otra íntima, en que se revela el espacio familiar. En tanto La infancia abre con la imagen proustiana del niño y sus miedos nocturnos, en Los días ocultos ella recién aparece en el cuarto capítulo, reformulada: "Tiemblo de miedo, a medianoche" (16), la que sintetiza y resta lirismo a la frase inaugural de La infancia. Hozven observa, también, que Los días ocultos "se inician emblemáticamente con la frase "Frente a la Plaza de Armas"' (34). Desde la perspectiva de mi análisis este cambio es importante no solo por el desplazamiento de lo íntimo y subjetivo al espacio de lo público y la objetividad (ese mayor "realismo" que observa Grau en este texto). Lo es también porque la mirada del narrador, presentificada en Los días ocultos, 
se va desplazando, recorriendo los rincones del pueblo y también los de los sueños del niño, como una cámara subjetiva que buscara instalarnos en un mundo movedizo, muy lejos de la fiebre estancada, del "imbunchamiento", como lo llama Hozven, de La infancia.

En Los días ocultos hay ascensos y descensos, vagabundeos:

Doblando la esquina, se llegaba a la Gobernación y al Correo [...] (7).

De pronto suspira profundamente. Nosotros no comprendemos nada. ¿Seré yo el causante? La sigo por la casa, sin atreverme a preguntar, tomado de su mano (11).

Rosalía debe ser un hada oculta. Camina lentamente y en puntillas, como una culebra (13).

Sigo lentamente en el sueño caminando a través de la casa, en la semioscuridad (17).

Nos trasladamos de súbito a la bodega otra vez [...] (19).

Bajamos a un país de nieve en que todo es engaño y ocultamiento. Todo se oculta. Todos se han ocultado de mí (21).

Pero hay también momentos agradables en estas pesadillas [...] Suelo recorrer aquellos bosques en donde crecen las plantas de algodón que se comunican con el cielo y mis pies adquieren alas. Otras veces desciendo al fondo del mar y escucho las sirenas de los barcos hundidos. Es delicioso avanzar debajo del agua. (26).

Vago por laderas de tierra oscura, en las que crecen plantas tibias, matorrales de tibios alientos [...] (26).

Pero lo más interesante para nosotros era gatear [...] sobre el campo cultivado de la alfombra, en este despacho que nos estaba siempre vedado (39).

Luego, por días y días, no conozco sino mi cama, mi refugio de largas temporadas. Este abismo tibio, de blancas sábanas, por el cual vago infinitamente, en el cual busco regiones frescas, para salir del tórrido estío de la fiebre (65).

En tanto La infancia transcurre principalmente en "el lecho", donde Eugenio padece su fiebre y sus enfermedades, en Los días ocultos el narrador se desplaza por los rincones del pueblo, de la casa y también de los sueños - "vamos de paseo" (18) le dice en uno de ellos la cocinera Rosalía-, lo que confiere dinamismo a su relato, una cartografía más elaborada y también, aparentemente, más distante de la experiencia infantil. De hecho, la madre de la fotografía ha cambiado ligeramente, cuando evoca:

la imagen de un retrato infantil en donde ella está vestida de estudiante, con largas trenzas sobre el cuello de marinero. A su lado, en la fotografía, hay una mata de aspidistra sobre un pedestal de madera y detrás un cortinaje en tono sepia que cae en largos pliegues. Domina la habitación una luminosidad rosada, como la de los sueños después del amanecer. Así continúa siendo ella en la rosa de sus zapatos que mueven rítmicamente al pedal (Oyarzún, Los días ocultos 11).

Como se puede ver, el niño en las pupilas -las niñas- de sus ojos, ha desaparecido y la evocación culmina con un retorno al presente - "Miro a mi madre que cose" (Oyarzún, Los días ocultos 11) - en que la necesidad de la unión y continuidad con lo materno -lo semiótico- se ha neutralizado, para dar curso a nuevos capítulos y experiencias. Fundamental 
es el crecimiento del personaje del tío abuelo materno del niño, quien cambia el nombre de José a Andrés y que aparece aquí encarnando un modelo de masculinidad que llama la atención del niño. "Él era la autoridad mayor en nuestra familia, no solo porque fuera el más viejo, el último hermano de mis abuelos, sino por esa fuerza contenida en sus pequeños ojos relampagueantes" (Oyarzún, Los días ocultos 43). Este tío les cuenta a Eugenio y sus hermanos que tienen antepasados indígenas (plantea una imagen histórica distorsionada para así justificar sus grandes orejas) y muchas otras historias: encarna un mundo oral, de historias populares. A veces huraño, otras veces cariñoso y consentidor, pero sobre todo con un mundo propio, el de su cuarto, que resulta atractivo al niño porque se trata de un "rincón legendario [...], misterioso y cerrado a mis incursiones" (Oyarzún, Los días ocultos 48). Poco aseado, fundamentalmente lector y andariego, el tío Andrés ostenta su historia como una medalla que refulge para el niño, admirado de las cartografías que ha trazado en sus innumerables y solitarios viajes a la costa: "Lentamente, de hito en hito, de tambo en tambo, el tío Andrés se acercaba al mar" (Oyarzún, Los días ocultos 60). Descreído de la política y de la vida moderna, este personaje encarna en realidad una opción de vida distinta, salvaje, libre, mágica, muy diferente del mundo de la oficina casera del padre, con su alfombra, su orden y sus horarios. Mientras en La infancia este se llamaba Pablo, en Los días ocultos el padre recibe el nombre de Rafael. No es el único cambio: muchos otros detalles hacen patente el deseo de redibujar esta figura, bajo una luz más benigna.

En La infancia, la infelicidad de la madre está dada principalmente por las ausencias y mentiras del esposo, quien parece querer esquivar la prisión de una familia llena de hijos y obligaciones. Las escenas de abandono y agresividad son varias, la mayoría suprimidas o atenuadas en Los días ocultos. Incluso hay un episodio en que la madre deja fuera de la habitación al padre, elidido en el texto de 1955. Los únicos momentos de felicidad plena, en La infancia, dicen relación con ese conflicto y su resolución: "Raras veces podemos ser todos felices, mis padres, mis hermanos y yo. No recuerdo un solo día entero perfecto. Solamente minutos fugaces, horas a lo sumo" (14). "Una tarde recorríamos un camino solitario [...] Al pasar, mi padre cogió un tomate de una planta florida y saboreó su perfume con fruición. Eso era la felicidad. Después, el camino polvoriento parecía perfumado por las frutillas que hacían amable toda la extensión de la tierra" (15). La felicidad se ve interrumpida, sin embargo, por la presencia de los amigos del padre. Ellos lo llaman en el camino, lo invitan a beber. Comienzan los conflictos, los silencios, el drama latente y apenas intuido por el niño en su sesgada comprensión del mundo de los adultos.

No quiero decir que en Los días ocultos las heridas hayan sido cauterizadas. Permanecen en su estado de latencia, pero parece que la fiebre sí ha desaparecido y que el niño de lluvia que es Eugenio ${ }^{6}$ ha logrado salir de la clausura que planteaba en la novela precedente.

6 Hernán Poblete sugiere esa relación con la novela homónima de Benjamín Subercaseaux. Por mi parte, me he referido en otro artículo (v. Referencias) a la relación entre los relatos de infancia de Oyarzún y los de aquel autor, como también a la proximidad con Epifanía de una sombra, de Mauricio Wacquez. En todos ellos aparecen figuras infantiles caracterizadas por su debilidad física, sus miedos, su fragilidad. 


\section{Conclusiones}

Ni en el ámbito filosófico ni en el literario, las obras de Oyarzún se inscriben sin más en un orden canónico, por lo que se hace necesario, para revalorizar su producción, leerlas a la luz de paradigmas que admitan la movilidad de los géneros escritos, la movilidad de las subjetividades, la movilidad de las miradas. Decía el escritor en su diario, siempre crítico de la sociedad chilena, que "[...] para llegar a la iluminación literaria se necesita una sensibilidad visual, una conciencia libre que acepta el mundo. La conciencia nuestra está traumatizada por la presencia de fantasmas interiores que empañan la visión. Quien ve un mundo de topos, no puede iluminar objeto alguno ni transformar estéticamente la realidad" (Oyarzún, Diario 79). Deseoso de ver, en una tradición de lo visual que traspasa la filosofía y la intelección occidentales, Oyarzún crea un relato de la infancia impregnado de sombra, de intuiciones, de iluminaciones a las que se aproxima por medio de una conciencia afiebrada y desplazada. Su propio trauma -toda infancia entraña alguno- es depurado a lo largo de años, con el fin de producir esa transformación estética que la filósofa Cecilia Sánchez subraya en un comentario sobre el Diario: "Oyarzún no permaneció en su yo, real, pues al dejarse llevar por su daimon interior, mal o bien, lo transmutó en escritura” ("Filosofía, literatura e identidad en la escritura de Luis Oyarzún" 31).

Para finalizar, llama la atención en esta singular búsqueda dentro de la historia literaria y filosófica chilena, una observación. Si se quiere, ante todo, una intuición. En La infancia, Eugenio aparece siempre enmudecido ante la madre, incapaz de decir aquello que realmente desea: su unión absoluta con ella. El relato pudiera ser la forma de tender los puentes que restablecen el apego a la madre, consolando no solo al hijo sino también a la propia madre-niña. En suma, resulta interesante explorar la idea de que estas búsquedas escriturales del filósofo -como sabemos, residuales, fragmentarias, fetichistas, tendidas a la naturaleza-, constituyen asedios o procuras simbólicas de la figura materna, en consonancia con lo que plantea Olga Grau y citábamos al comienzo de este artículo, la posibilidad de ver en estas dos novelas una infancia de la escritura, producto del gesto inaugural, autobiográfico, de Oyarzún.

\section{Referencias}

Amaro, Lorena. "Wacquez y sus precursores: infancia, género y nación”. Revista Chilena de Literatura 85 (2014). Medio impreso inédito.

Benjamin, Walter. "El surrealismo (la última instantánea de la inteligencia europea)". Iluminaciones I. Madrid: Taurus, 1993. 41-62. Medio impreso.

---. "La obra de arte en la época de su reproductibilidad técnica”. Discursos interrumpidos I. Buenos Aires: Taurus, 1989. 17-60. Medio impreso.

Gignoux, Anne-Claire. “De l'intertextualité à lécriture”, Cahiers de Narratologie 13 (2006). $<$ http://narratologie.revues.org/329>. Fecha de ingreso: 20 de mayo de 2013. Sitio web. 
Grau, Olga. "La infancia en una escritura”. Teoría y práctica en filosofía con niños y jóvenes. Experimentar el pensar, pensar la experiencia. Comp. Walter O. Kohan. Buenos Aires: Centro de Publicaciones Educativas y Material Didáctico, 2006. 183-93. Medio impreso.

Hozven, Roberto. Escritura de alta tensión. Santiago de Chile: Catalonia, 2010. Medio impreso.

Jay, Martin. "El lamento por la crisis de la experiencia. Benjamin y Adorno". Cantos de experiencia. Variaciones modernas sobre un tema universal. Buenos Aires: Paidós, 2009. 365-417. Medio impreso.

Millas, Jorge. "Luis Oyarzún o la pasión de ver”. Defensa de la Tierra. Santiago de Chile: Universitaria, 1973. IX-XXV. Medio impreso.

Morales, Leonidas. "El diario de Luis Oyarzún”. Cyberhumanitatis 18 (2001). http://www. revistas.uchile.cl/index.php/RCH/article/viewArticle/8910/8788. Fecha de ingreso: 5 de octubre de 2013. Sitio web.

Oyarzún, Luis. Diario íntimo. Edición y prólogo de Leonidas Morales. Santiago de Chile: Departamento de Estudios Humanísticos de la Universidad de Chile, 1995. Medio impreso.

---. Epistolario familiar. Selección de Tomás Harris, Claudia Tapia y Pedro Pablo Zegers, prólogo de Alfonso Calderón. Santiago de Chile: Dibam / Lom, 2000. Medio impreso.

---. La infancia. Santiago de Chile: Ediciones Revista Nueva, 1940. Medio impreso.

---. Los días ocultos. Santiago de Chile: Pacífico, 1955. Medio impreso.

---. Temas de la cultura chilena. Santiago de Chile: Universitaria, 1967. Medio impreso.

Pérez Villalón, Fernando. "Variaciones sobre el viaje (dos viajeros ejemplares: Mistral y Oyarzún). Revista Chilena de Literatura 64 (2004). 47-72. http://www.scielo.cl/ scielo.php?pid=S0718-22952004000100003\&script=sci_arttext. Fecha de ingreso: 5 de octubre de 2013. Sitio web.

Poblete, Hernán. “Luis Oyarzún Peña (1920-1972)”. Taken for a ride. Escritura de paso. Compilación y prólogo de Thomas Harris, Daniela Schütte y Pedro Pablo Zegers. Santiago de Chile: RIL, Archivo del Escritor, 2005. 436-48. Medio impreso.

Sánchez, Cecilia. Escenas del cuerpo escindido. Ensayos cruzados de filosofía, literatura y arte. Santiago de Chile: Universidad Arcis / Cuarto Propio, 2005. Medio impreso.

---. "Filosofía, literatura e intimidad en la escritura de Luis Oyarzún". Hispamérica 110 (2008). 15-32. Medio impreso. 